\title{
Metode Location Based Service Dalam Mengurangi Resiko Tersesat Saat Pendakian Gunung Menggunakan Global Positioning System (GPS)
}

\author{
Danan Rifandi Nugroho ${ }^{1}$, Asep Ramdhani Mahbub ${ }^{1,{ }^{*}}$, Tri Dharma Putra ${ }^{1}$ \\ ${ }^{1}$ Fakultas Teknik, Universitas Bhayangkara Jakarta Raya; Jl. Raya Perjuangan, Marga \\ Mulya, Bekasi Utara, Jawa Barat 17121. Telp: 021-88955882, 889955883, e-mail: \\ danan.rifandi@gmail.com; aseprm@dsn.ubharajaya.ac.id; \\ tri.dharma.putra@dsn.ubharajaya.ac.id \\ * Korespondensi: e-mail: aseprm@dsn.ubharajaya.ac.id
}

Diterima: 9 Mei 2020 ; Review: 10 Mei 2020; Disetujui: 27 Mei 2020; Diterbitkan: 17 Juni 2020

\begin{abstract}
Climbing in Indonesia from year to year has increased the demand. More and more climbers are interested in this activity but increasingly also accidents that occur in the mountain due to lack of knowledge and discipline of climbers. The mountaineering guide app is made to help climbers to plan preparations before climbing and while climbing the mountains, this app also features a mountain position layout and path from basecamp, climbing posts to the top, and can request evacuation requests at TimSAR. By using the technology of Global Positioning System and Location Based Service climbers can easily find the point where it is located, and can minimize accidents and even death that can occur in the mountain.
\end{abstract}

Keywords: Mountaineer, Location Based Service, Global Positioning System, Mountain Climbing Guide.

\begin{abstract}
Abstrak
Pendakian di Indonesia dari tahun ke tahun mengalami peningkatan peminatnya. Semakin banyak pendaki yang meminati kegiatan ini tetapi semakin bertambah pula kecelakaan yang terjadi di gunung akibat kurangnya pengetahuan dan kedisiplinan pendaki. Aplikasi panduan mendaki gunung dibuat untuk membantu para pendaki untuk merencanakan persiapan sebelum mendaki dan saat mendaki gunung, aplikasi ini juga dilengkapi dengan tata letak posisi gunung dan jalur dari basecamp, pos-pos pendakian sampai ke puncak, dan dapat meminta permintaan evakuasi pada TimSAR. Dengan menggunakan teknologi Global Positioning System dan Location Based Service pendaki dapat dengan mudah mencari titik posisinya berada, dan dapat meminimalisir kecelakaan bahkan kematian yang dapat terjadi di gunung.
\end{abstract}

Kata kunci: Pendaki Gunung, Location Based Service, Global Positioning System, Panduan Mendaki Gunung.

\section{Pendahuluan}

Mendaki gunung salah satu olahraga keras penuh petualangan di alam terbuka menuju ke tempat yang lebih tinggi ke puncak gunung. Mendaki gunung membutuhkan keterampilan, kecerdasan, kekuatan, dan daya juang yang tinggi. Keberhasilan suatu pendakian bukan berapa tinggi kalian medaki dan mencapai puncak gunung, tetapi keberhasilan suatu pendakian adalah bagaimana kalian bisa sampai kerumah masing-masing dengan selamat kembali. 


\section{Danan Rifandi Nugroho, Asep Ramdhani Mahbub, Tri Dharma Putra}

Keberhasilan suatu kegiatan di alam terbuka juga ditentukan oleh perencanaan perjalanan, perlengkapan dan perbekalan yang tepat serta persiapan pribadi para pendaki itu sendiri. Mengingat pentingnya suatu perencanaan dalam mempersiapkan kegiatan mendaki gunung, para pendaki harus teliti agar tidak terjadi kesalahan yang berakibat fatal membahayakan diri pendaki itu sendiri. Banyak kejadian buruk yang bisa terjadi pada saat pendakian gunung apabila seorang pendaki gunung mengabaikan hal-hal yang disebutkan diatas contohnya tersesat, jatuh ke jurang, kehabisan perbekalan, kedinginan, kelelahan, sulit bernafas, kaki keram, kesurupan, di terjang cuaca buruk, terkena tumbuhan liar atau hewan liar, bahkan kematian.

GPS (Global Positioning System) adalah sistem untuk menentukan posisi dan navigasi secara global dengan memanfaatkan satelit. Sistem yang pertama kali dikembangkan oleh departemen pertahanan Amerika ini digunakan untuk kepentingan militer maupun sipil. GPS (Global Positioning System) atau yang biasa disebut LBS (Location Based Service) memiliki unsur utama yaitu Location Manager (API Maps) menyediakan perangkat bagi sumber atau source untuk LBS dan Location Provider (API Location) menyediakan teknologi pencarian lokasi yang digunakan oleh perangkat. LBS dapat berfungsi sebagai layanan untuk mengidentifikasi lokasi dari seseorang atau suatu objek tertentu (Maulana, 2014).

Sebagian besar orang telah bergantung pada mobile device untuk memperoleh informasi yang cepat, mudah dan tepat. Maka dari itu diperlukan sistem informasi untuk merencanakan perjalanan sebelum mendaki gunung. Jadi sistem aplikasi ini informasi dilengkapi dengan bagaimana merencanakan perjalanan pendakian, mempersiapkan kondisi fisik, perlengkapan dan perbekalan, pertolongan pertama pendakian gunung (PPGD), serta memanfaatkan GPS (Global Positioning System) untuk menentukan jalur pendakian, agar dapat mengurangi resiko kematiaan saat mendaki gunung dengan menggunakan smartphone android.

Perancangan terdiri dari dua komponen utama yaitu perancangan perangkat keras meliputi perancangan arsitektur serta perancangan perangkat lunak yang meliputi perancangan database yang berupa ERD (Entity Relationalship Diagram) dan perancangan sistem yang dapat berupa DFD (Data Flow Diagram) (Eriani, 2013).

Aplikasi merupakan program yang dikembangkan untuk memenuhi kebutuhan pengguna dalam menjalankan pekerjaan tertentu. Jadi aplikasi merupakan sebuah program yang dibuat dalam sebuah perangkat lunak dengan komputer untuk memudahkan pekerjaan atau tugas-tugas seperti penerapan, penggunaan dan penambahan data yang sudah dibutuhkan (Yuhefizar, 2012).

Berdasarkan wawancara yang penulis lakukan di PKD MAPALA JABODETABEKA (Pusat Kordinasi Daerah Mahasiswa Pecinta Alam Jakarta, Bogor, Depok, Tanggerang, Bekasi, Karawang), penyebab utama banyaknya kasus pendaki yang tersesat, hilang bahkan meninggal dunia di gunung dikarenakan sulitnya mencari dan memahami informasi tentang merencanakan perjalanan bahkan mempersiapkan perlengkapan dan perbekalan yang tepat. 
Sehingga banyak sekali pendaki dengan kecerobohan, mendaki dengan perlengkapan dan perbekalan yang seadanya bahkan tidak mengetahui perencanaan perjalanan.

Taman Nasional Gunung gede pangrango adalah salah satu gunung yang paling banyak diminati pendaki, Karena letaknya yang tidak jauh dari perkotaan TNGGP merupakan tempat yang sering didaki oleh pendaki dalam negri maupun yang luar negri, berikut adalah statistik pendaki TNGGP.

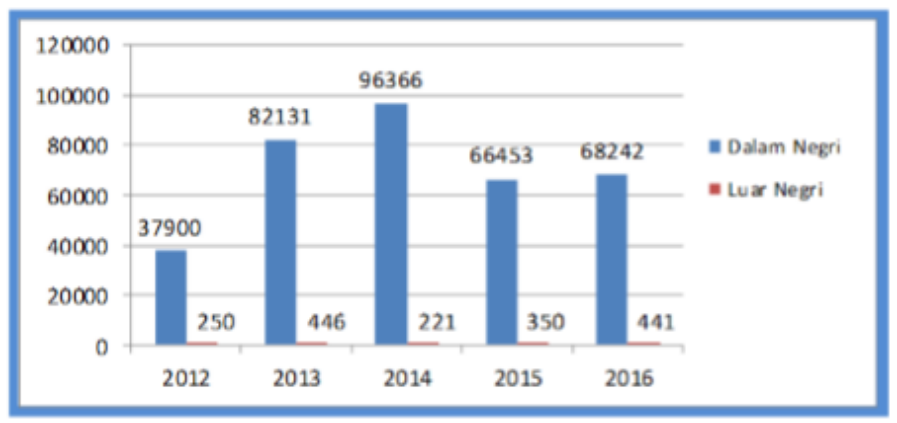

Sumber: (Taman Nasional Gunung Gede Pangrango)

Gambar 1. Statistik Pendaki TNGGP

Sering sekali para pendaki pemula menganggap mendaki gunung adalah sebagai rekreasi biasa, salah satunya di Gunung gede pangrango saat sedang pengecekan ulang peralatan dan perbekalan yang dilakukan oleh petugas pintu masuk TNGGP, masih banyak pendaki yang menyepelekan persiapan untuk mendaki gunung. Karena mengabaikan persiapan dari peralatan maupun perbekalan yang mereka bawa, tidak jarang dari pendaki yang mengalami musibah saat mendaki gunung. Selain peralatan dan perbekalan yang dibawa, pendaki harus memperhatikan fisiknya apakah cukup sehat, cukup kuat, pengetahuannya tentang membaca dan menentukan jalur dengan menggunakan peta dan kompas cukup mahir, karena tidak adanya rambu atau petunjuk yang jelas di gunung, dan siapkah mereka dengan ilmu PPGD yang sewaktu-waktu musibah bisa saja terjadi.

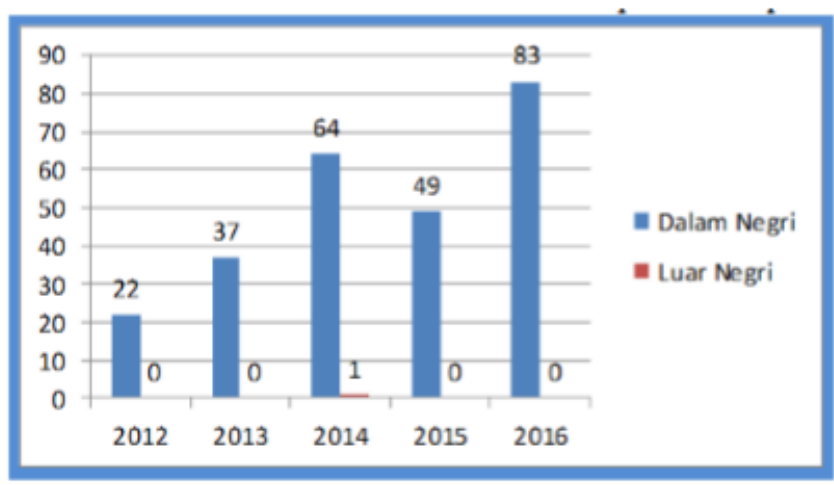

Sumber: (Taman Nasional Gunung Gede Pangrango)

Gambar 2. Statistik Kecelakaan Wisata TNGGP

Gambar 2 adalah data kecelakaan wisatawan di Taman Nasional Gunung Gede Pangrango, Bogor Jawa Barat. Data kecelakaan dari tahun 2012 sampai dengan 2016 


\section{Danan Rifandi Nugroho, Asep Ramdhani Mahbub, Tri Dharma Putra}

mengalami kenaikan korban kecelakaan, sempat turun di tahun 2015 namun di tahun 2016 korban bertambah hampir 2 kali lipat.

\section{Metode Penelitian}

Dalam melakukan penelitian perlu adanya metode penelitian yang digunakan, dan di dalam penelitian ini menggunanakan metode dalam tahap mengumpulkan data, analisis dan perancangan.

Metode Pengumpulan Data yang digunakan dalam pengumpulan data adalah wawancara, observasi, studi pustaka, kuesioner. 1. Wawancara dilakukan dengan memberikan beberapa pertanyaan kepada ketua divisi gunung hutan mapala (Mahasiswa Pecinta Alam) dan pendaki professional kota Bekasi untuk menganalisa permasalahan dan pemecahan masalah. 2. Observasi dilakukan dengan terjun langsung ke lapangan untuk menganalisa dan pengumpulan data dalam pembuatan aplikasi yang diusulkan. 3. Studi Pustaka dilakukan dengan mempelajari teori yang dibutuhkan dalam penelitian ini, agar dapat membantu dalam penelitian ini dalam langkah analisa ataupun dalam penulisannya. 4. Kuesioner Teknik pengumpulan data yang dilakukan dengan cara menggunakan daftar pertanyaan yang diberikan kepada beberapa responden (sample) dalam suatu organisasi.

Metode pengembangan sistem yang digunakan dalam penelitian ini adalah Rapid Application Development (RAD), yang dilakukan dengan tahapan sebagai berikut: 1 . Pemodelan bisnis Tahapan untuk mengumpulakan kebutuhan informasi yang terkait dalam penelitian ini. 2. Pemodelan data Tahapan mengumpulan data yang terkait dengan informasi yang sudah dikumpulkan dan menjadikan data yang dikumpulkan menjadi informasi. 3. Pemodelan proses Menerapkan informasi dan data yang sudah didapatkan untuk diproses menjadi satu informasi yang siap untuk diimplemetasikan. 4. Pembuatan aplikasi Tahapan ini adalah tahap selanjutnya untuk membuat sebuah sistem yang diusulkan berdasarkan informasi yang sudah diproses dari pengumpulan informasi dan data. 5. Pengujian dan pergantian Tahapan ini adalah tahapan untuk melakukan pengujian pada sistem yang diusulkan, jika semua sudah teruji maka tahapan pengembangan sistem selesai.

Rapid Application Development (RAD) adalah model proses pengembangan perangkat lunak yang bersifat inkremental terutama untuk waktu pengerjaan yang pendek. Model RAD adalah adaptasi dari model air terjun versi kecepatan tinggi dengan menggunakan model air terjun untuk pengembangan setiap komponen perangkat lunak (Sukamto \& Shalahuddin, 2015).

Kelebihan Metode Rapid Application Development (RAD): 1. Sangat berguna jika user tidak memahami kebutuhan apa saja yang digunakan pada proses pengembangan perangkat lunak. 2. RAD mengikuti tahapan pengembangan sistem yang sama dengan metode pengembangan yang lainnya, tetapi mempunyai suatu kemampuan untuk menggunakan kembali komponen - komponen yang ada (reusable object) sehingga pengembang tidak perlu membuat dari awal lagi dan penggunaan waktu menjadi lebih singkat berkisar antara 60 - 90 hari. 3. Karena mempunyai kemampuan untuk menggunakan komponen yang sudah ada dan 
waktu pengerjaan yang lebih singkat maka memungkinkan dapat menghemat biaya dan menghasikan produk yang berkualitas.

Kelemahan Metode Rapid Application Development (RAD): 1. Untuk pembuatan sistem perangkat lunak dengan sekala besar maka model RAD akan memerlukan sumber daya manusia yang cukup besar untuk membentuk tim-tim yang mengembangkan komponenkomponen. 2. Jika tidak ada persetujuan untuk mengembangkan perangkat lunak secara dengan cepat (rapid) maka proyek dengan model ini akan gagal karena hanya bingung mendefinisikan kebutuhan pelanggan (customer) atau user. 3. Jika sistem perangkat lunak yang akan dibuat tidak bisa dimodulkan (dibagi - bagi menjadi beberapa komponen) maka model RAD tidak dapat digunakan untuk membuat sistem perangkat lunak ini karena terlalu banyak campur tangan antar tim. 4. Model RAD tidak cocok digunakan untuk sistem perangkat lunak yang memiliki risiko teknis sangat tinggi, misalnya menggunakan teknologi baru yang belum banyak dikenal dan dikuasai pengembang.

\section{Hasil dan Pembahasan}

GPS (Global Positioning System) adalah sistem untuk menentukan posisi dan navigasi secara global dengan memanfaatkan satelit. Sistem yang pertama kali dikembangkan oleh departemen pertahanan Amerika ini digunakan untuk kepentingan militer maupun sipil (Maulana, 2014). Sistem GPS, yang nama aslinya adalah NAVSTAR (Navigation Satelite Timing and Rangging Global Positioning System), terdapat tiga kriteria yaitu: Satelit, pengontrol, dan penerima atau pengguna. Satelit GPS yang mengelilingi bumi, dengan orbit dam kedudukan koordinat yang pasti, seluruhnya berjumlah 24 buah dimana 21 buah aktif berkerja dan 3 buah sisanya adalah cadangan. Jadi GPS adalah suatu sistem navigasi yang menghubungkan tempat atau lokasi dimana kita berada ke lokasi yang akan menjadi tujuan memanfaatkan fungsi dari satelit.

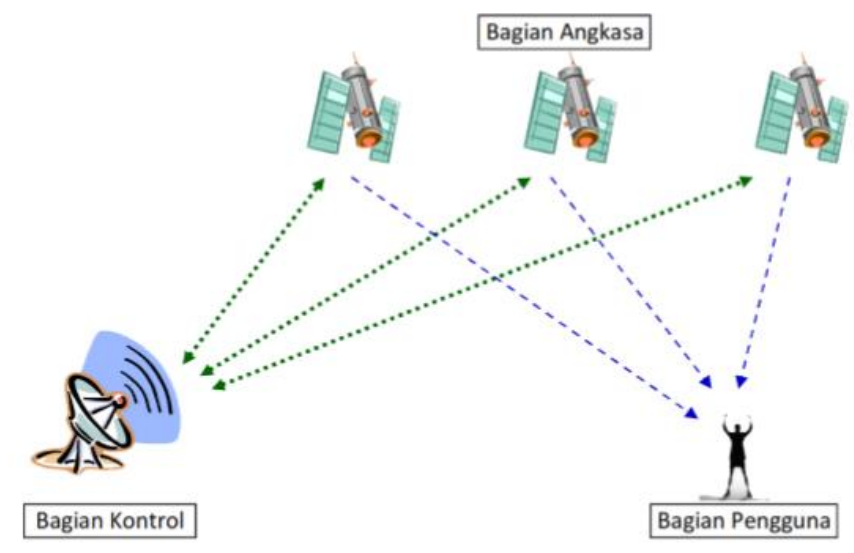

Sumber: www.camargus.com

Gambar 3. Cara Kerja GPS 


\section{Danan Rifandi Nugroho, Asep Ramdhani Mahbub, Tri Dharma Putra}

Sistem ini menggunakan sejumlah satelit yang berada di orbit bumi, yang memancarkan sinyalnya ke bumi dan ditangkap oleh sebuah alat penerima. Ada tiga bagian penting dari sistim ini, yaitu bagian kontrol, bagian angkasa, dan bagian pengguna.

LBS (Location Based Service) merupakan suatu layanan yang bereaksi aktif terhadap perubahan entitas posisi sehingga mampu mendeteksi letak objek dan memberikan layanan sesuai dengan letak objek yang telah diketahui tersebut (Safaat, 2015). Pada teknologi LBS berbasis jaringan seluler, penentuan posisi sebuah peralatan komunikasi bergerak ditentukan berdasarkan posisi relative peralatan tersebut terhadap lokasi BTS (Base Transceiver Station).

Oleh karena itu pengguna memberitahu penyedia layanan untuk mendapatkan informasi yang dia butuhkan, dengan referensi posisi pengguna tersebut. Layanan berbasis lokasi dapat digambarkan sebagai suatu layanan yang berada pada pertemuan tiga teknologi yaitu: geographic information system, internet service, dan mobile device.

Secara garis besar layanan berbasis lokasi atau LBS terdiri dari 5 komponen utama antara lain: 1) Mobile Device: sebuah alat yang digunakan untuk meminta informasi yang dibutuhkan. 2). Communication Network: jaringan selular yang mengirimkan data pengguna dan permintaan layanan. 3) Positioning Component: untuk pengolahan layanan biasanya posisi pengguna harus ditentukan. Posisi pengguna dapat diperoleh menggunakan jaringan komunikasi dengan menggunakan Global Positioning System (GPS). 4) Service and Application Provider: penyedia layanan pengguna selular yang bertanggung jawab untuk memproses layanan. 5) Data and Content Provider: penyedia layanan informasi data yang dimita oleh pengguna.

Use case diagram pada perancangan ini bertujuan untuk menjelaskan bagaimana interaksi antara actor dengan sistem dan apa saja yang berjalan pada sistem tersebut. Use case diagram sistem usulan ini terbagi atas tiga bagian, yaitu dari sisi administrator, sisi tim SAR dan sisi pendaki. Berikut adalah model UML use case diagram dari sistem usulan yang akan dirancang.

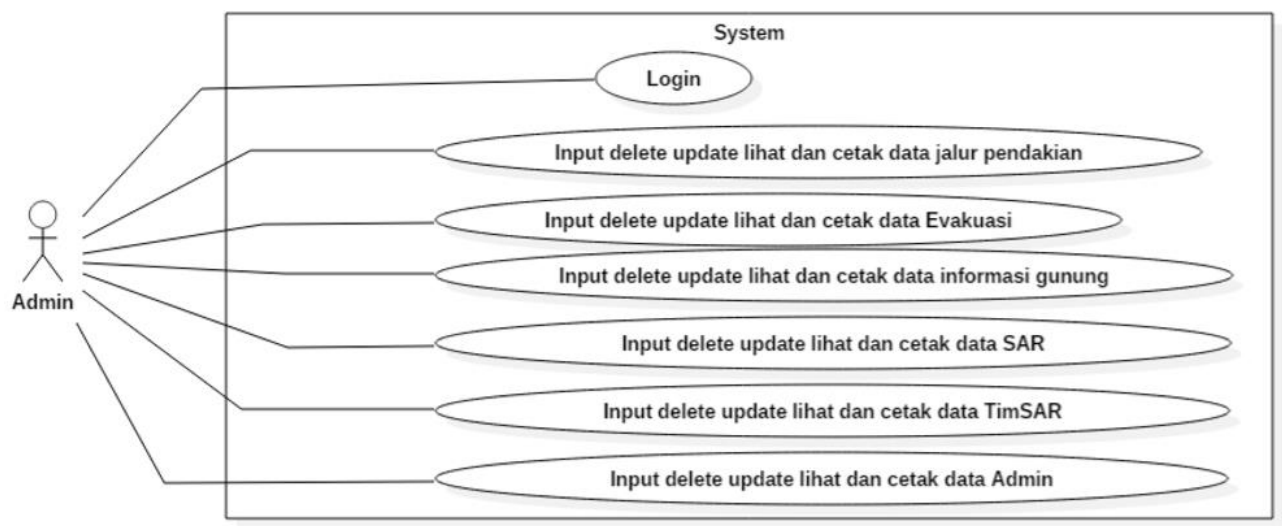

Sumber: Hasil Penelitian (2017)

Gambar 4. Usecase Sistem Usulan Admin 
Gambar 4 menjelaskan tentang usecase sistem usulan admin. Terdiri dari 7 usecase dan 1 actor.

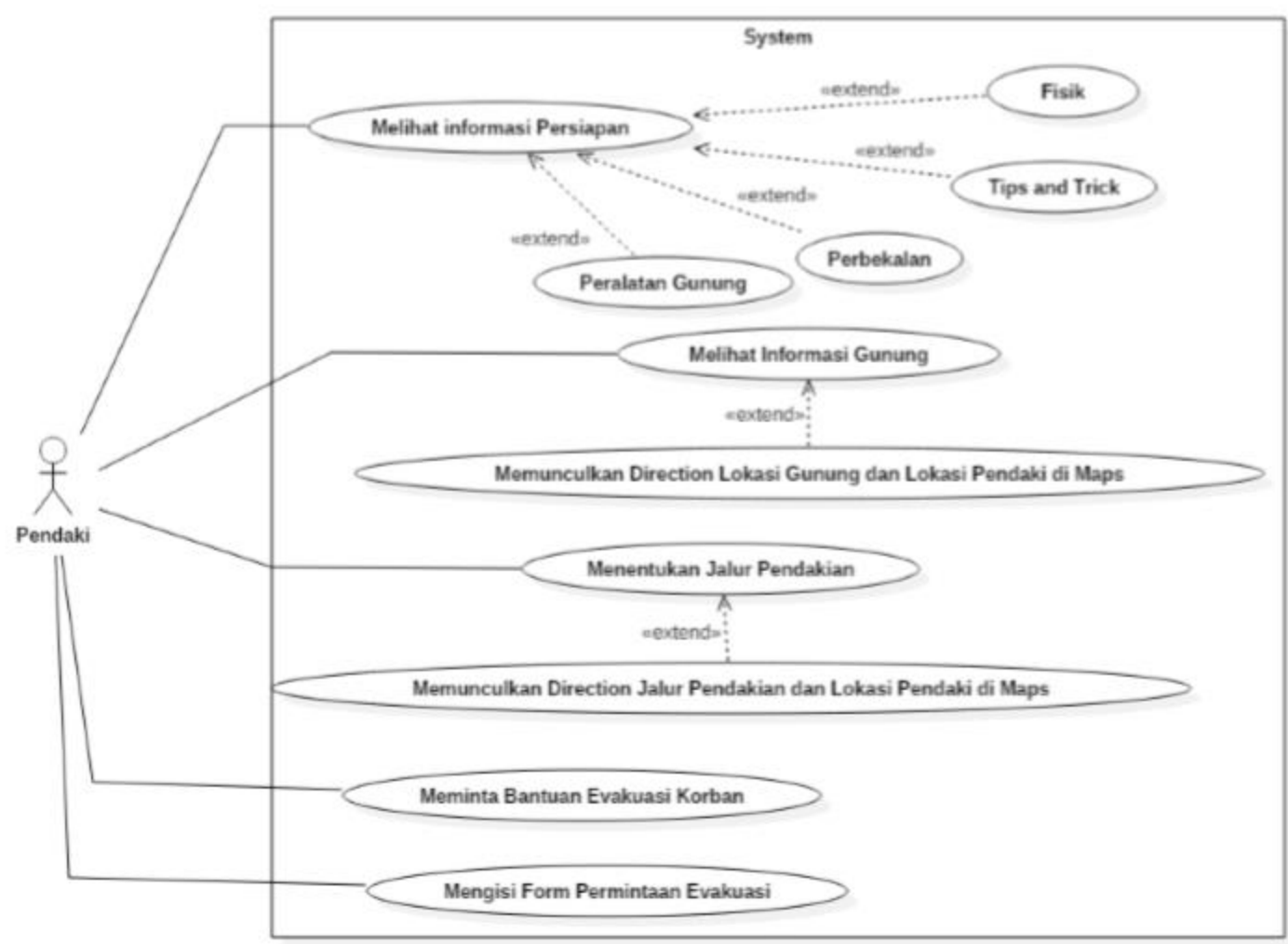

Sumber: Hasil Penelitian (2017)

Gambar 5. Usecase Sistem Usulan Pendaki

Gambar 5 menjelaskan tentang usecase sistem usulan pemdaki. Terdiri dari 11 usecase dan 1 actor.

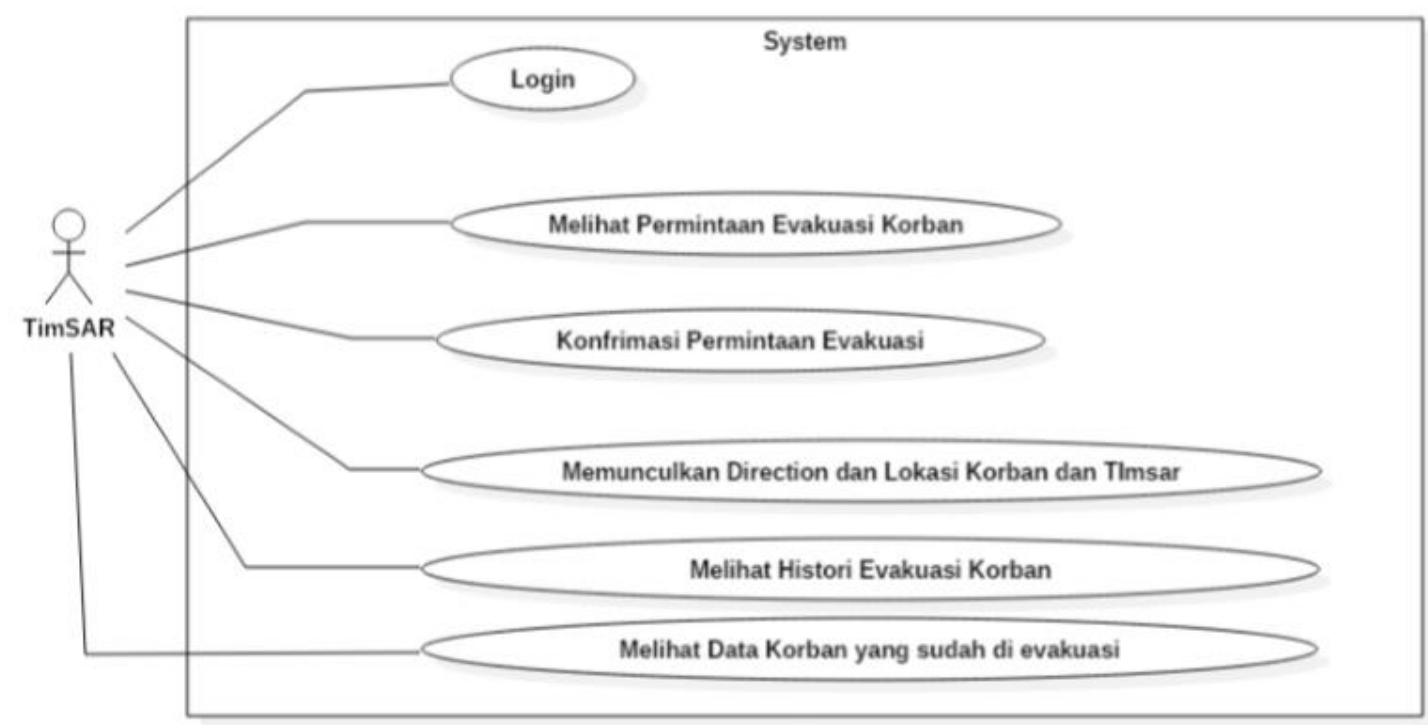

Sumber: Hasil Penelitian (2017)

Gambar 6. Usecase Sistem Usulan TimSAR 
Gambar 6 menjelaskan tentang usecase sistem usulan timSAR. Terdiri dari 6 usecase dan 1 actor.

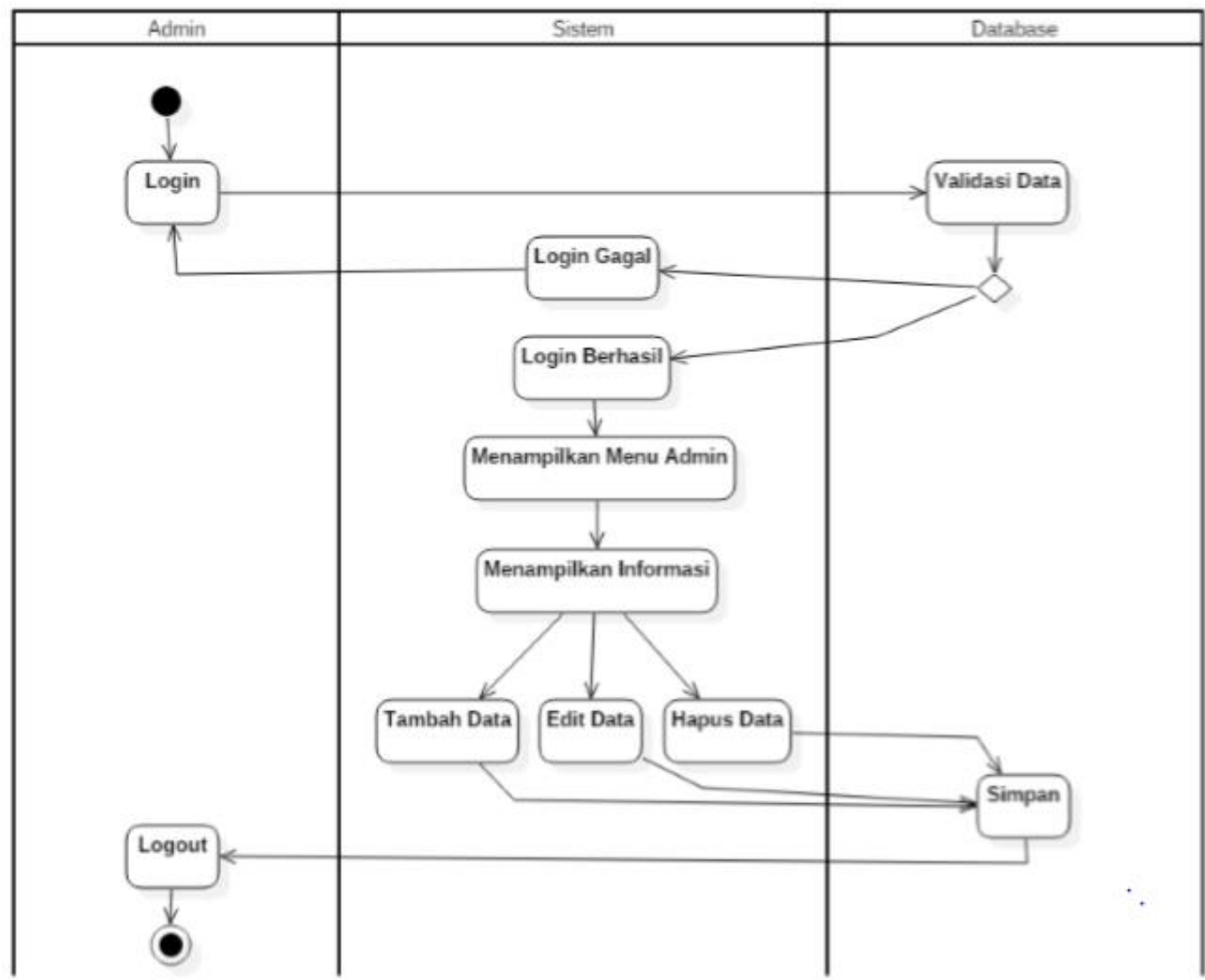

Sumber: Hasil Penelitian (2017)

Gambar 7. Activity Diagram Kelola Infromasi dan Data

Gambar 7 menjelaskan tentang activity diagram Kelola Informasi dan data. Terdiri dari 6 usecase dan 1 actor.

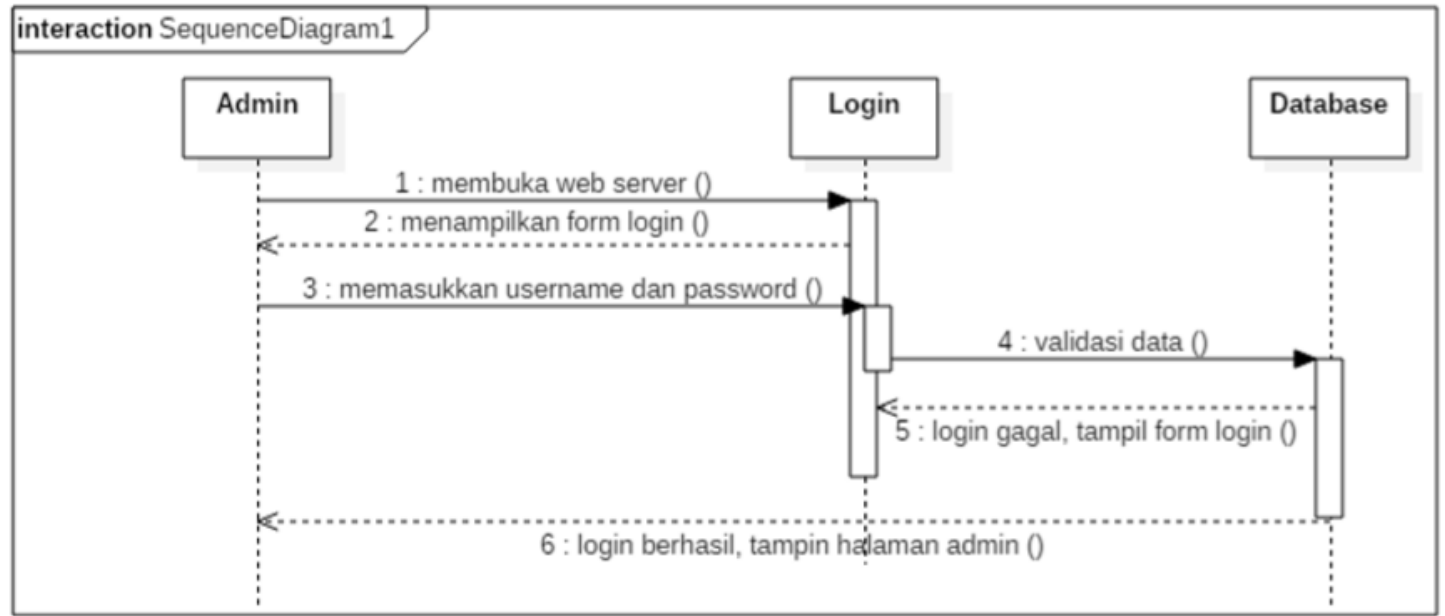

Sumber: Hasil Penelitian (2017) 


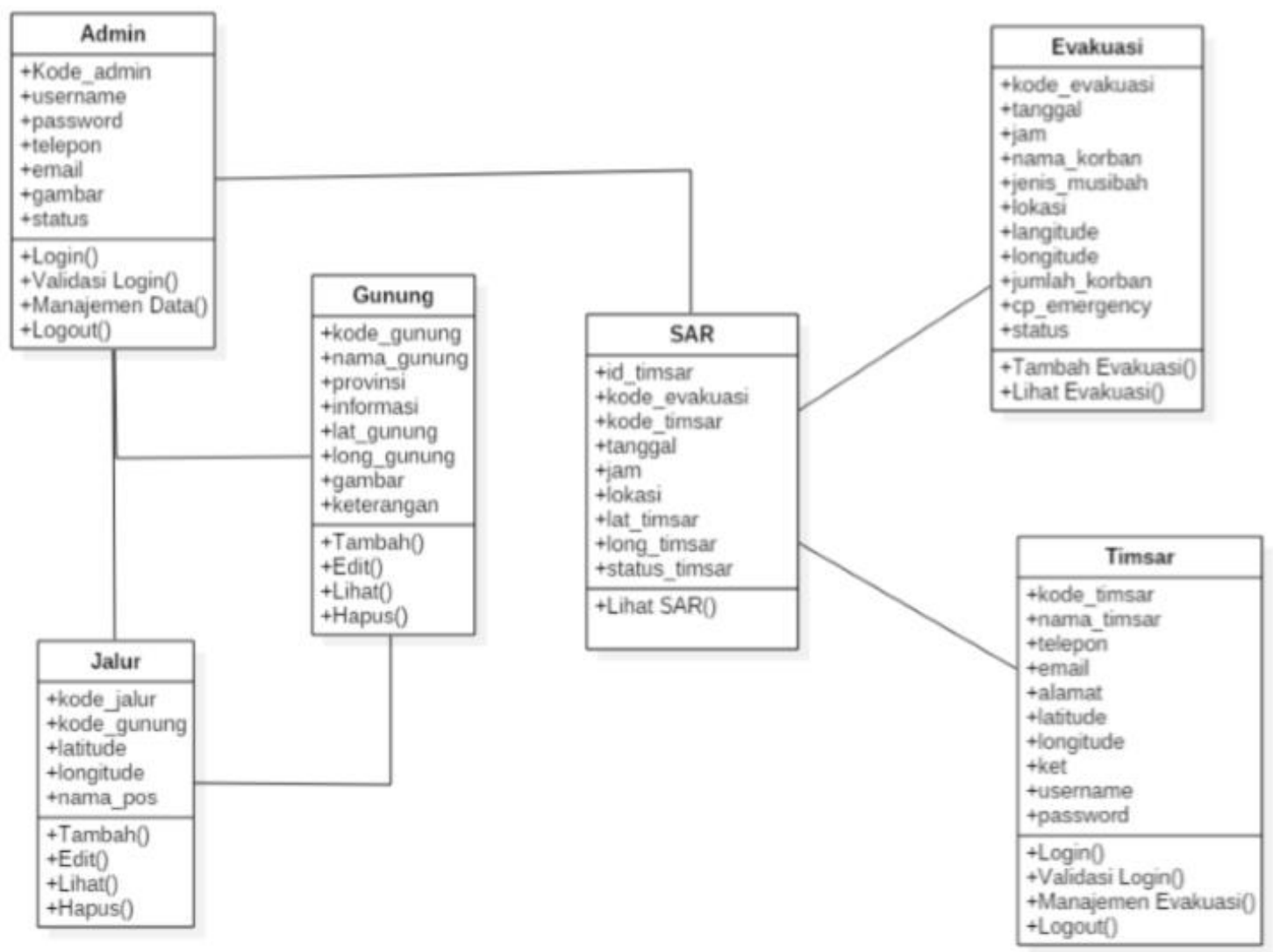

Sumber: Hasil Penelitian (2017)

Gambar 9. Class Diagram Sistem Usulan

Setelah dilakukan tahap desain sistem dan coding maka akan menghasilkan tampilan sistem yang telah dibuat, maka berikut adalah gambar-gambar hasil tampilan dari aplikasi panduan mendaki gunung:

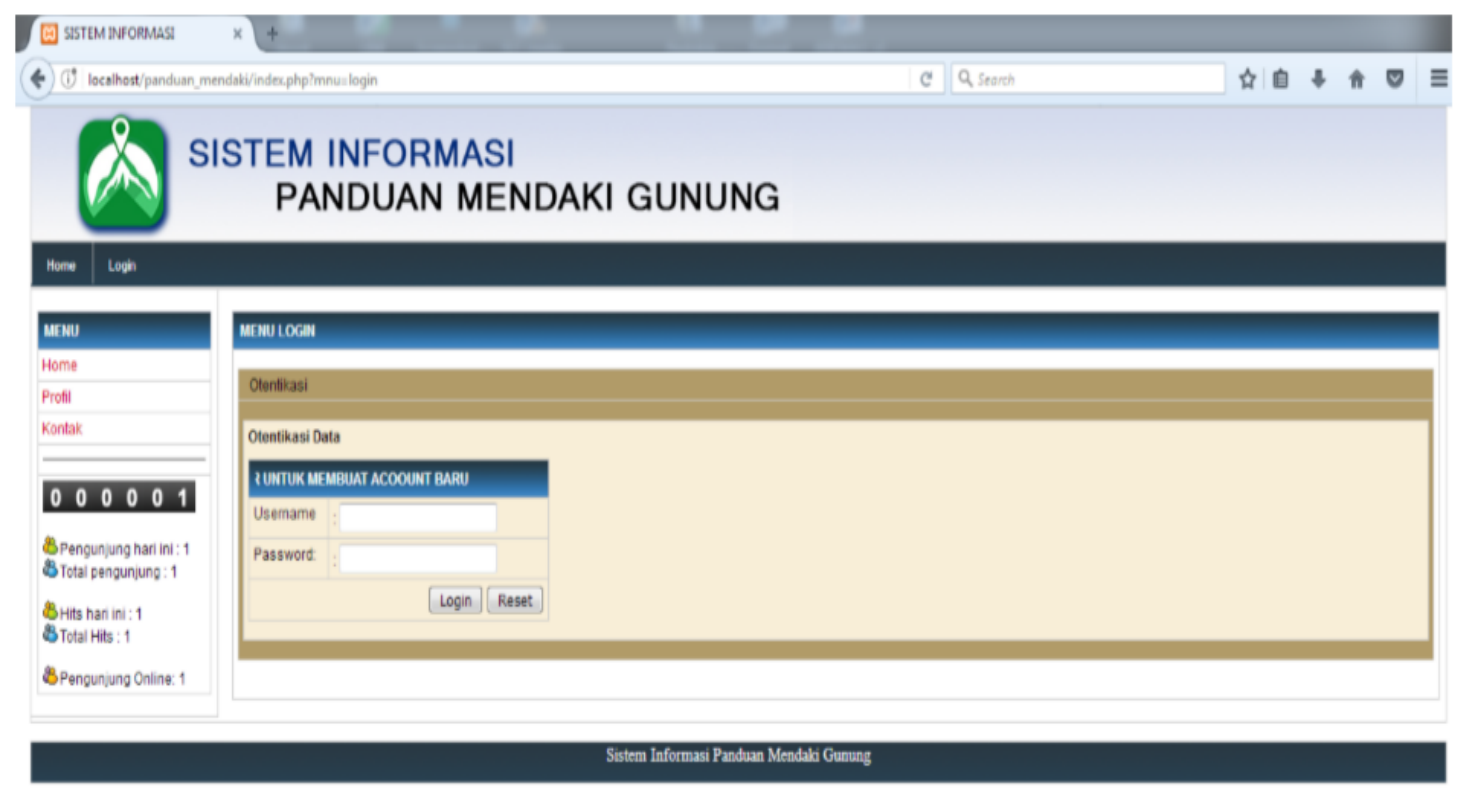

Sumber: Hasil Penelitian (2017) 
Gambar 10 merupakan Halaman Login admin pada tampilan desainnya, sedangkan pada Gambar 11 menjelaskan tentang halaman utma pendaki.

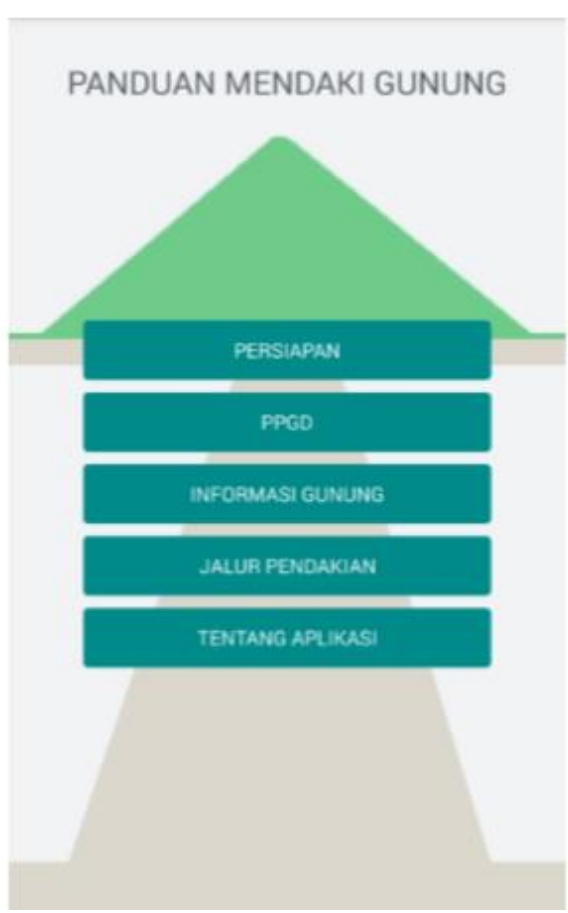

Sumber: Hasil Penelitian (2017)

Gambar 11. Halaman Utama Pendaki

Gambar 12 merupakan Halaman sub menu persiapan pada tampilan desainnya, sedangkan pada Gambar 13 menjelaskan tentang halaman menu PPGD.

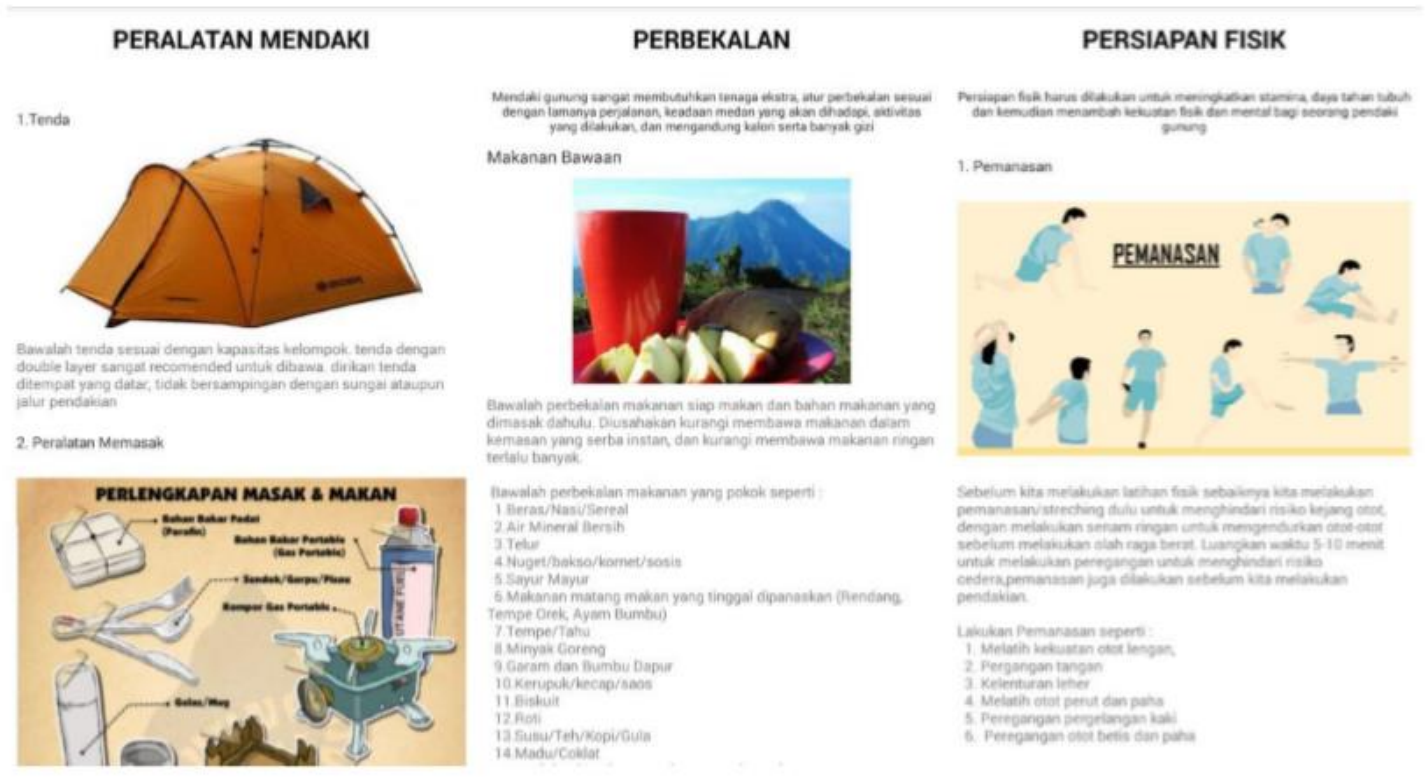

Sumber: Hasil Penelitian (2017) 


\section{PENANGANAN PERTAMA GAWAT DARURAT}

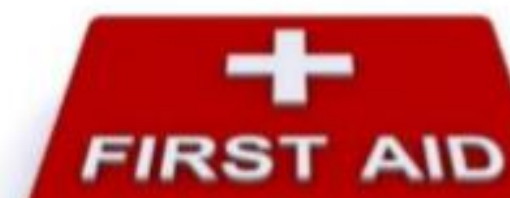

PPCD

PENDARAHAN

\section{SHOCK}

\section{PATAH TULANG}

\section{TERKILIR}

\section{IUKA-IUKA}

Sumber: Hasil Penelitian (2017)

Gambar 13. Halaman Menu PPGD

Gambar 14 merupakan Halaman sub menu PPGD pada tampilan desainnya, yang terdiri dari menu pendarahan, terkilir/keseleo, dan hypothermia.

\section{PENDARAHAN}

Pada nast kecelakaan terjodt dan meryebabiany

1. Pendarahan Kapile: Pendarahan ini biasarya tergadi pada pembuluh darah
kecil pado kulit.

2. Pendarahan Vena.

Pendarahan ini berasal pembuluh vena, perbuluth Weh plinn daph merah mtay merah marnon berware gelap

3. Arteri.

Tipe pendarahan Arteri berpotensi paling berbahaye Ciltandal dengan semburan darah berwama merat?

terang

Menangani pendarahan kapiler dan vena. Pendarahan kapiler dan pendarahan wena odnah du Jenis pendarahan yaryg paling umum. Kats dapart

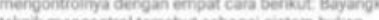

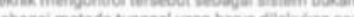
sebagai thetr.

1. Penekanan langsung

Melakikan tekanan langsung pada likas dengan perber

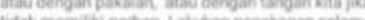

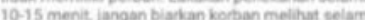

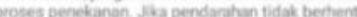
fakikan kembali penekanan selama 15 menit
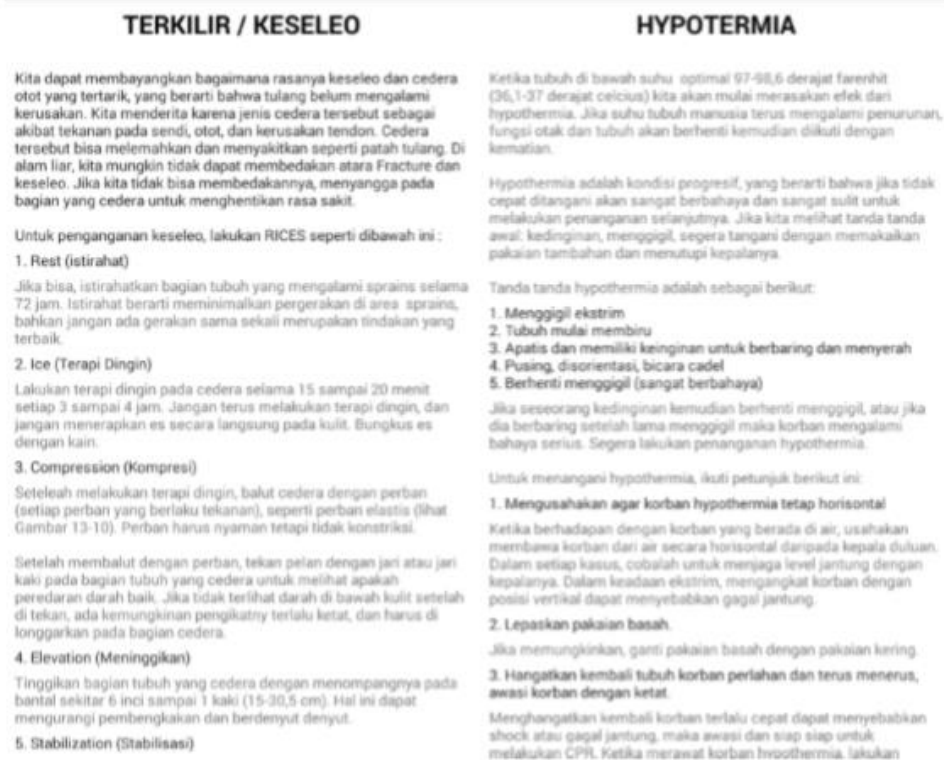

Sumber: Hasil Penelitian (2017) 


\section{Danan Rifandi Nugroho, Asep Ramdhani Mahbub, Tri Dharma Putra}

Gambar 15 merupakan Halaman Direction Gunung dan Pendaki di Googlemaps pada tampilan desainnya, sedangkan pada Gambar 16 menjelaskan tentang Halaman Lokasi Jalur Pendakian.

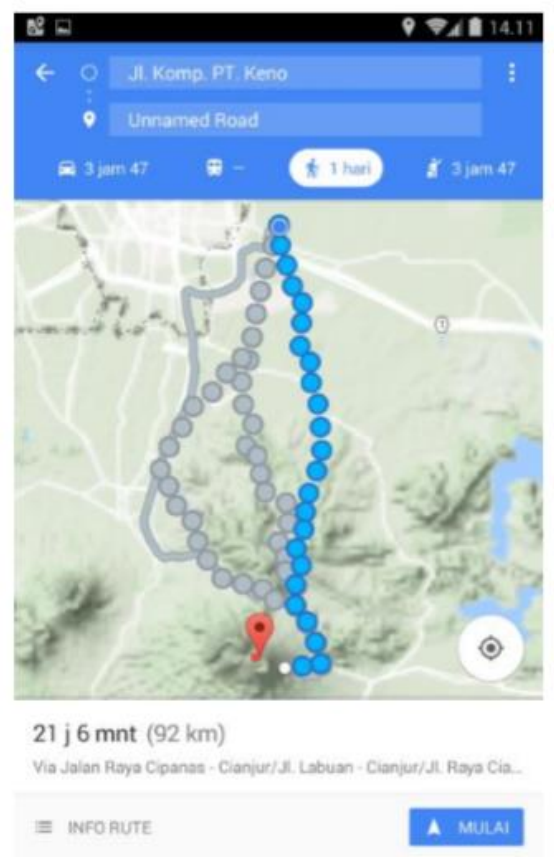

Sumber: Hasil Penelitian (2017)

Gambar 15. Halaman Direction Gunung dan Pendaki di Googlemaps

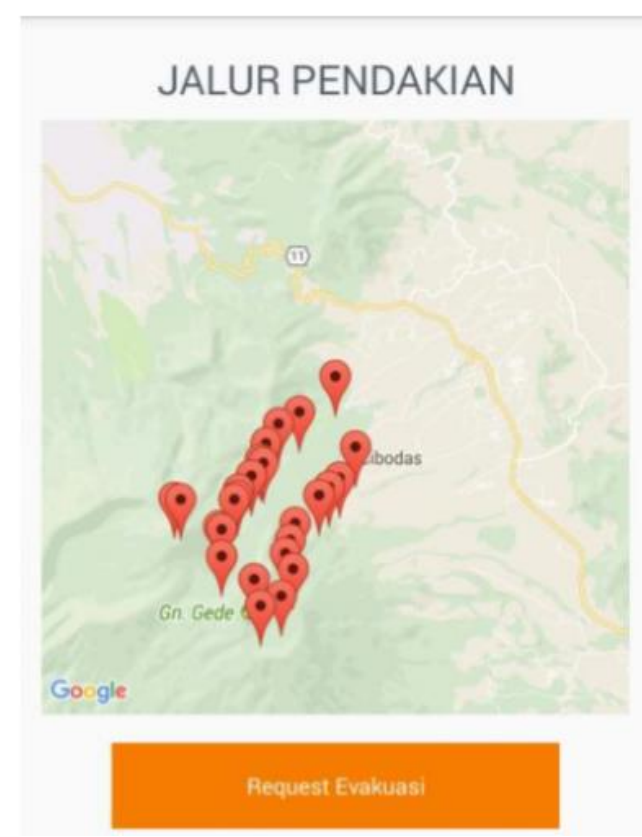

Sumber: Hasil Penelitian (2017)

Gambar 16. Halaman Lokasi Jalur Pendakian 


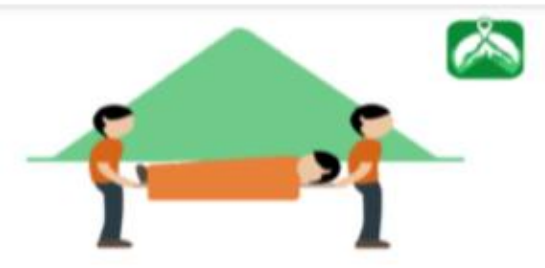

\section{MENU TIMSAR}

Selamat Datang Timsar

PERMINTAAN EVAKUASI

DATAEVAKUASI

DATAKORBAN

\section{LOGOUT}

Sumber: Hasil Penelitian (2017)

Gambar 17. Halaman Utama Menu TimSAR

Gambar 17 merupakan Halaman utama menu TimSAR pada tampilan desainnya, terdiri dari permintaan evakuasi, data evakuasi, data korban dan logout.

\section{Kesimpulan}

Berdasarkan hasil perancangan aplikasi panduan mendaki gunung menggunakan GPS (Global Positioniong System) dengan metode LBS (Location Based Service) untuk mengurangi resiko tersesat, maka dapat diambil kesimpulan sebagai berikut: 1) Aplikasi panduan mendaki gunung membantu para pendaki untuk mendapatkan informasi tentang perencanaan sebelum mendaki yang sesuai dengan SOP (Standar Operasional Pendakian). 2) Aplikasi panduan mendaki gunung dilengkapi dengan informasi tentang PPGD (Penanganan Pertama Gawat Darurat) untuk korban saat terjadi musibah saat pendakian. 3). Aplikasi ini dilengkapi dengan informasi gunung dan lokasi gunung-gunung yang hanya berada di pulau jawa saja. 4). Aplikasi panduan mendaki gunung dilengkapi untuk pemilihan jalur pendakian dalam tiap-tiap gunung yang ada di Jawa barat. 5). Dalam aplikasi ini pendaki dapat meminta pertolongan evakuasi ke timsar tanpa harus datang langsung ke basecamp yang dapat memakan waktu lebih banyak. Untuk dapat menunjang jalannya program dalam pengimplementasian aplikasi panduan mendaki gunung yang telah dibuat, maka terdapat beberapa saran sebagai berikut: 1) Dalam penelitian selanjutkan bisa ditambahkan fitur tracking pendaki, dalam sisi TimSAR dapat memonitoring lokasi pendaki secara realtime. 2) Untuk penelitian selanjutnya disarankan menambahkan menu perkiraan cuaca serta informasi keadaan terupdate tentang kondisi di suatu gunung tersebut pada aplikasi ini dan notifikasi email untuk TimSAR jika mendapatkan request evakuasi dari pendaki. 3). Dalam penelitian selanjutnya disarankan sistem dapat dikembangkan lebih lanjut dengan menambahkan fitur pendaftaran pendaki secara online di 
smartphone. 4). Pada sisi pengguna disarankan menggunakan provider yang kuat sinyal, karena untuk menggunakan aplikasi ini agar berjalan dengan optimal maka dibutuhkan koneksivitas internet yang cepat dan sinyal provider yang kuat. 5). Gunakan baterai cadangan untuk menggunakan aplikasi ini, karena daya yang dibutuhkan sangat besar.

\section{Daftar Pustaka}

Eriani, S. (2013). Perancangan Sistem Informasi Pendaftaran Training Berbasis Web Pada LKP. Balaraja Cendekia Graha STMIK Raharja.

Maulana, I. (2014). Pengukuran GPS Geodetik dan Terresial Leser (TSL) Untuk Pembangunan Rel Kereta Api Baru di Menteng Jaya Jakarta.

Safaat, N. H. (2015). Rancang Bangun Aplikasi Multiplatform. Informatika.

Sukamto, R. A., \& Shalahuddin, M. (2015). Rekayasa Perangkat Lunak. Informatika.

Yuhefizar. (2012). CMM Website Interaktif MCMS Joomla (CMS). Gramedia. 